\title{
The 2010 Gigascale Imperative: Why the instruction of electronics technology must change!
}

\author{
By Gary J. Mullett \\ Springfield Technical Community College, Springfield, Massachusetts
}

\begin{abstract}
Approximately four decades have past since the first implementations of two-year college electronics programs with curricula recommended by the United States government. Today's electronics programs look remarkable similar to those early programs. This paper contends that there needs to be substantial change to how electronics technology is taught or the skill sets of tomorrow's graduates will becomes even more disconnected from the world of work than they are today. This change needs to embrace and emphasis a systems level approach to the teaching of electronics technology along with an infusion of the Scan's report soft skills into the curriculum. Several suggestions of how this may be accomplished are presented here.
\end{abstract}

\section{Overview}

Approximately forty years have past since the implementation of the first government recommended two-year college electronics curricula. Although tremendous technologic change has occurred in the electronics field and its manufacturing industry, little change has occurred in the typical curriculum leading to an associate degree in this area. Except for the continuous and rapid accretion of new technical subject matter into the typical curriculum, today's programs look remarkable similar to those of the early 1960s. This paper contends that there needs to be a rapid and pervasive systemic change to electronics technology education now or there is a real danger that the skill sets of tomorrow's graduates will become even more disconnected from the world of work than they presently are. This change needs to embrace and emphasis a systems level approach to the teaching of electronics technology along with a meaningful infusion of the Scan's report soft skills into the curriculum.

During the early 1960s, the United States Office of Education, under the then Department of Health, Education, and Welfare, prepared curriculum guides to assist the States in the development of technical education programs. The guide for Electronics Technology was extensively used to design new electronics programs at the post-secondary level ${ }^{[1]}$. The stated goal of the curricula proposed by the guide was to produce competent technicians that could work with engineers and scientists: doing research and development work or serving as customer (field) service, operations (manufacturing), and communications technicians. As already stated, although forty years has past and incredible technological change has occurred in the field, little change has occurred in the typical curriculum leading to a degree in the electronics area. Even with the addition of new technical subject matter into the typical curriculum, today's programs look remarkably similar to the one proposed in the original guide ${ }^{[2]}$.

In a closely related matter, beginning in the mid-1980s, the field of engineering education started to respond to numerous reports that there needs to be changes made to engineering education. An 
increased emphasis on synthesis and design, open-ended problem solving, development of management and communications skills, professional development, and career-long learning are all included in this call for change. This response was in reaction to a perceived need to correct a decade's long emphasis on engineering science that occurred post-World War II tilting the engineering education field away from engineering practice and the new realities of a global economy that demands skill sets not emphasized at the time. In a similar manner, the technical education community at the two-year college level has, in a synergistic manner, started to embrace similar elements of the Scans report ${ }^{[3]}$ (usually, problem solving skills and life-long learning) with efforts to infuse these so-called "soft skills" within the technology curriculum. The engineering education community has recently initiated a new program, The Engineer of 2020: Visions of Engineering in the New Century, sponsored by the National Academy of Engineering which continues to question the type of education needed to prepare engineers for the world of the future ${ }^{[4]}$. For the most part, this program is focusing in on several key areas; the interdisciplinary context of emerging fields, communication skills, the diversity of the future workforce, and the increasing systems like nature of future engineering products. All of these areas certainly pertain to technician level education also.

Furthermore, over the past twenty-five years there has been a good deal of research conducted about contextual learning and learning styles by the ever developing field of cognitive science. These areas of research are quite important to the field of technical education, at both the twoand four-year level. A large number of the students that enter two-year associate degree programs come from the middle portion $\left(25^{\text {th }}-75^{\text {th }}\right.$ percentile) of high school students. For this group, learning styles play an important role in a student's success or lack thereof. At the same time, research has shown that the "graying faculty" of the post-secondary community college system tend to teach like they were taught (i.e. lectures or abstractly) while studies indicate that the typical student in this group has a tendency to learn in a concrete (experiencing/feeling) manner. It is this author's contention that most post-secondary faculty have had very little exposure to these new theories and typically reveal a resistance to embracing new teaching techniques without appropriate support and/or materials for guidance in the ways in which these new teaching techniques might be implemented. Additionally, many researchers have found that students learn more and retain what is learned longer if it is learned in context - that is, applied to real world situations. For a typical technology based curriculum that consists of a sequence of stand-alone self-contained courses that are taught in isolation, such courses do not readily lend themselves to this type of instruction. These factors pose a daunting problem if we are trying to allow the typical technical education student to reach their full potential and also fill the need for a skilled technical workforce at the same time.

Finally, ABET, the recognized accreditor for both university and college engineering and engineering technology programs has adopted a new criteria known as ABET 2000. This criteria adds a new component to the technical education mix, that of continuous quality improvement. ABET's goal is to assure quality education and innovation in technical and engineering education. For two-year ABET accredited programs, this new criteria will hopefully prompt the program faculty to become proactive in looking at some of the issues mentioned here.

II. The future is almost here 
As the electronics industry enters the era of gigascale devices, tremendous change is about to occur in the design of tomorrow's electronic devices, systems, and products. At the very least, these electronics based systems will be able to be reconfigured either by a technician or under their own embedded control, they will have the capability of wireless connectivity, and they will be more easily dealt with through software than any hands-on activity. Combining semiconductor gigascale technology with emerging nanotechnology will create a new class of reconfigurable and eventually evolvable, electronic/biomedical/mechanical/photonic systems on a chip (SOC). Researchers have already begun to examine how this change will affect future products. The recently formed Gigascale Systems Research Center (GSRC) is focusing on three areas; "the problems of the small, the problems of the large, and the problems of the diverse". These areas, while related to specific engineering design challenges ${ }^{[5]}$, will directly effect how a technician deals with these future technology systems.

III. Using the OSI model

Instead of belaboring a long and involved history of the state of electronics in an attempt to correlate the required skill sets needed by the electronics technician, let us use another vehicle to illustrate this evolution from yesterday, to today, and into the future. If one borrows concepts from the OSI model for communication between networked systems (see Figure 1), one could justifiably say that for years, the physical layer or layer 1 of the OSI model, has been the focal point of the classical electronics technology education.

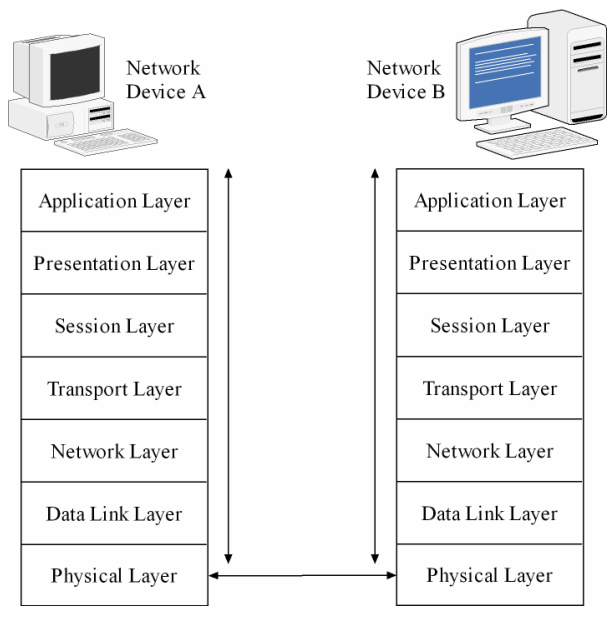

Figure 1 The OSI Model

The physical layer is the "electronics" of the system and it performs whatever function the system was designed for. During the very early years of electronics, the devices used to build a system remained fairly constant in their characteristics with incremental changes gradually occurring in their performance and reliability. The vacuum tube era is representative of this type of system operation. The typical electronic based system was fixed in its purpose/operation and only human intervention could change its operational characteristics (e.g. tuning a radio, adjusting a volume control, rewiring a programming instruction, etc). With the advent of the transistor (a disruptive technology), electronics systems became more functionally complex and an era of more rapid technologic change began. With the smaller sized transistor and eventually 
the first integrated circuits, systems with much more complexity were able to be designed and implemented. Video delivery systems (i.e. televisions) became commonplace and digital computer systems that formerly filled rooms became smaller, more complex, less expensive, and more useful. In general, electronic communications systems tended to be analog in nature and fixed in their operation while computers and digital systems used logic gates, were designed with Boolean algebra, and used programming languages (software) to control and alter the flow of their operations. In any case, the physical layer analogy of these devices is of a fixed hardware structure that can not be reconfigured to perform new functions without physical intervention.

During this latter time period, the electronics technician was tasked with the installation, service, and maintenance of systems built with discrete devices. Since most electronics equipment was expensive, big and bulky, and tended to malfunction or get out of alignment fairly easily due to the typical failure mechanisms of the day, this type of technology got repaired if it experienced any type of failure or incorrect operation. Electronics technology was expensive and innovations did not occur rapidly enough to warrant the replacement of a failed system by a totally new system as is the typical case today.

IV. Early electronics technology education

As electronics applications and products became more commonplace, the need for a workforce of electronics technicians to deal with the design, manufacturing, and the maintenance of consumer products and those of business and industry grew (hence, the proliferation of electronics programs at the two-year college level). Again, since the typical failure mechanism of that era's technology was the malfunction of a discrete part or component, repair of the electronic system depended upon the technician's knowledge of the system's operation and the operation of the individual parts that comprised the electronics products of the day. As new technology implementations like the phase locked-loop or combinational digital logic circuits where introduced in integrated circuit (IC) form, for the technician, essential nothing changed in terms of needed skills except for the additional knowledge of how these new devices functioned. It was natural for the curricula of this era to consist of stand-alone courses that provided information about the building blocks of both analog and digital systems since this type of knowledge facilitated the troubleshooting of a system to the part level, at which point it could be repaired. If a new technology implementation like "microcontrollers" built up a large enough body of knowledge, a new course would be added into the curriculum typically at the expense of some other non-technical course.

For the field of electronics technology, the era of semiconductor microminiaturization marched to the beat of Moore's law and consequently the rapid development of the computer and subsequently the microprocessor, and eventually the PC followed. Early on, the ever increasing installed base of digital computers was growing rapidly and the functionality of entire computer electronics systems was becoming more complicated. As a result, during the late 1970s to early 1980s, numerous computer technology programs spun off from the legacy electronics programs. These new programs maintained a heavy emphasis on electronics fundamentals but added courses on computer hardware and software. In this case, it was felt that the body of knowledge was just too large to be included in the legacy electronics program but instead merited a separate program of its own.

\footnotetext{
"Proceedings of the 2005 American Society of Engineering Education Annual Conference and Exposition Copyright $($ C 2005, American Society of Engineering Education"
} 
V. Status of today's electronics technology

Fast forwarding to today, the subsequent decades have brought more rapid and dramatic change to electronics technology and related spin off technologies (photonics, telecommunications, robotics, etc) most of which the genesis of, can again, be traced back to amazing advances in semiconductor microminiaturization technology (once more, Moore's law). Again, in many cases, legacy electronics programs and their derivatives have morphed simply by the accretion of new material into the curricula. In almost all cases, electronics programs have become PC centric since most complex electronics systems have become softer and softer, increasingly relying on software for both control and maintenance functions. Even the classic test equipment used by the technician has continued to converge towards the PC as many of the functions performed by these instruments are now performed in conjunction with a PC or are embodied in low cost circuit simulation software.

As mentioned earlier, gigascale integrated circuits with increased functionality and near gigascale reconfigurable cores now exist. Built in self test (BIST) and designed for testability (DFT) technology for these ICs is maturing. The ability to produce efficient and reliable systems that can be reconfigured or can reconfigure themselves is near at hand. With this in mind, let's re-examine the physical implementation, or physical layer of today's electronic systems, the embodiment of the system itself. To some, it is obvious, that for complex systems, layer 1 has evolved to consist of several identifiable sub-layers if you will (see Figure 2). It is this author's contention that today the physical layer frequently (and most likely more often in the future) consists of two to three sub-layers. As labeled in Figure 2, sub layer 1a (the system device layer) consists of passive and active electronic components, memory, core sub-systems, and possibly other related technology components (mechanical, photonic, biomedical, etc) that may be either fixed in their function or able to be reconfigured under electrical control. Sub layer $1 \mathrm{~b}$ (the system configuration layer) consists of embedded controllers/microprocessors or other specialized processing cores that are able to be directed in their operation under software control. These devices are typically used to interface to and control the functioning of the layer 1a devices and cores. Finally, a master or supervisory sub-layer labeled as 1c overlays the bottom two sub-layers. Typically a generic processor with its higher level operating system exists at this layer (the system interface and control layer) to control and interface to the layer $1 \mathrm{~b}$ devices. In many cases today, what has been labeled as layer 1c in Figure 2 is physically implemented as a separate piece of equipment and physically located at some distance from layers $1 \mathrm{a}$ and $1 \mathrm{~b}$ hardware. Control functions are passed over a standard network connection using standard protocols or communicated to the hardware itself through some type of direct craft interface port. Typically for this last case, a laptop computer serves as the hardware device that implements the functionality of this control layer while the lower layers are considered to be managed objects (MOs). An example of this type of structure is provided by today's cellular telephone system hardware. For instance, consider the cellular base station controller (BSC) that is usually located at some distance from the radio base station (RBS). Today, these two system elements are typically networked together. What will these devices look like five years from now? It is hard to predict the exact make-up but one thing is sure, they will not be larger and more disparate units than they are today. Most likely they will be co-located and considered to be one physical unit in the near future. 


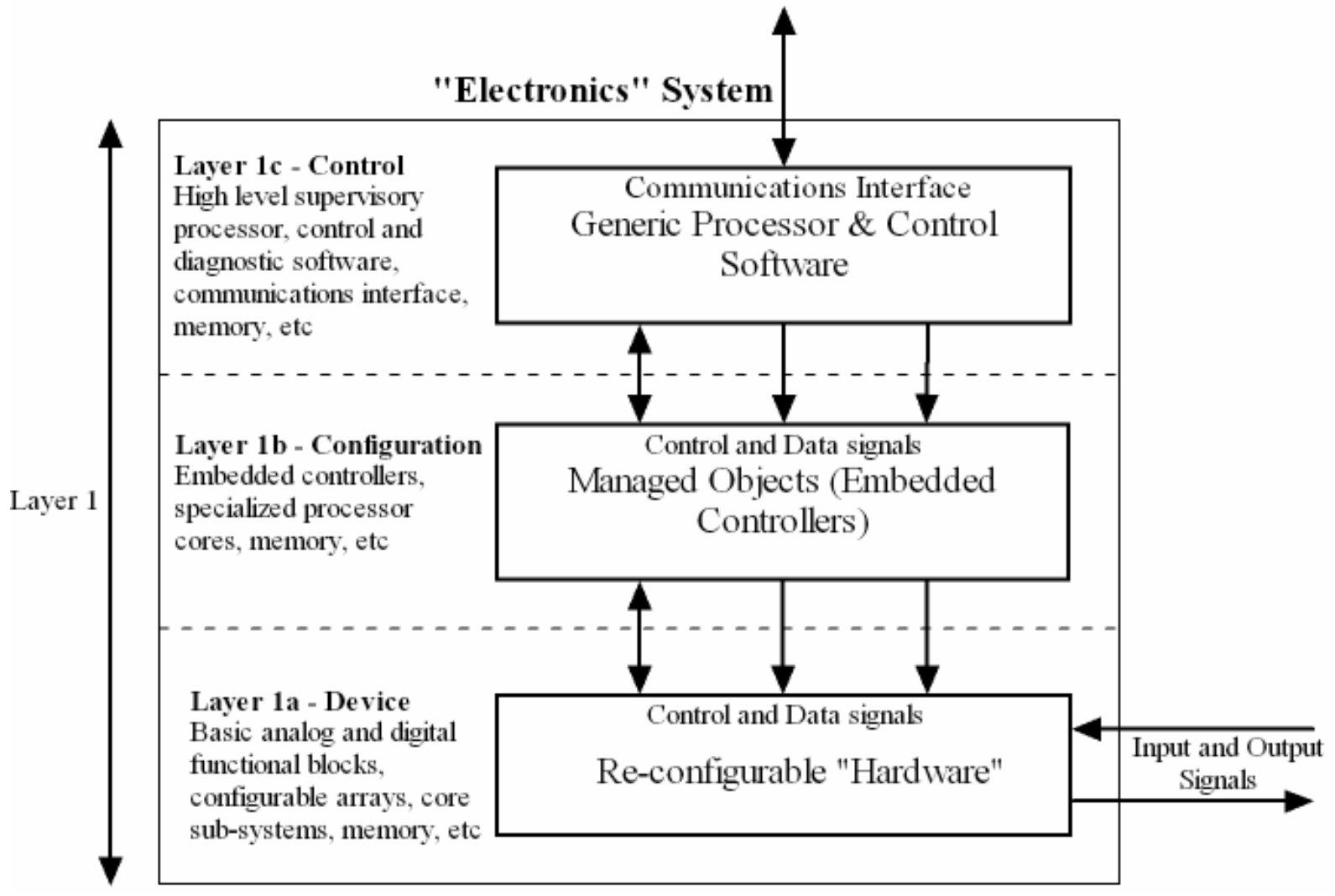

Figure 2 - Layer 1 sublayers

This brings up another point about today's complex electronic systems. Using the OSI model to describe how the same cellular base station controller controls a radio base station from a distance, would necessarily involve the concepts of networking, various transmission protocols, and discussion of OSI layer 1,2, and 3 operations. Certainly, the electronics technician of today and the future will need to be versed in the theory of networking and/or telecommunication technology!

To summarize, in the future, it is predicted ${ }^{[6]}$ that most complex electronic systems will be constructed from semiconductor cores (i.e. gigascale ICs that contain basic building block arrays of analog and digital sub-systems, various embedded processors, memory, and other crossdisciplinary nanotechnology sensors and components) since application specific ICs are predicted to become too expensive to design and produce. These building block core components will provide sub layer $1 \mathrm{a}$ and $1 \mathrm{~b}$ functionality while a more generic processor will used to interface with these heterogeneous subsystems and the ultimate system user. Typical layer 1c functions of overall system control, communications with other systems, software up-dating, system diagnostics, and various other system activities will be very likely provided by this generic processor. As sure as technology will move forward, these software controlled sub-layers will become the gateways to the hardware systems of the future. 
These types of systems are already being devised (e.g. software defined radios, cognitive radio systems, reconfigurable computers, etc) and will be become more common place as time goes on. This is exciting stuff but where does it leave the electronics technician? Most hardware will be dealt with by software, faulty field replaceable units will be swapped out, and very little repair will be possible at the part level (in some fields this is already the norm!). The implication is that the skill sets of the "electronics technician" in the not to distant future will require considerable cross-disciplinary systems knowledge, networking and telecommunications expertise, and computer software skills along with legacy mechanical skills and the mandatory people skills necessary to function in a diverse workforce competing in global economy.

\section{Present status of electronics education}

What are we teaching today's technician? Many electronics instructors still insist upon teaching fundamental electronics theory to the part level. This is most likely due to a reluctance to change what they have been doing for many years, a personal disconnect from modern day industry needs, and, to some extent, reliance upon the materials sold by book publishers for these introductory topics. This last point needs to be expanded upon. It has been this author's observation that over the last several decades there has been fierce competition amongst publishers to capture market share for textbooks used to teach electric circuits, analog electronics, and digital electronics (courses common to most electronics type programs and thus having the highest enrollments and hence the highest profit potential). Talk to anyone who teaches this type of material and almost anyone who is asked can name the best selling authors of these expensive texts that are presently into their nth printing. These "cash cows" were first written when it was proper to teach to the part level. As competition between publishers increased, authors added all kinds of ancillary materials and covered every aspect of the topic down to the finest degree of granularity imaginable without invoking higher mathematics. The publishers have added multiple color printing, CD ROMs with Power Point ${ }^{\mathrm{TM}}$ presentations and more recently web site support. Today these best sellers are on average close to one thousand pages in length. These books are certainly not conducive to teaching in any way but to a part level. Furthermore, one can cite many examples where the material contained in the text has little connection to the real world of electronics systems of today (e.g. no mention of class D amplifiers, use of thirty year old 7400 logic, etc). Amazingly, most popular electronics devices texts still devote numerous chapters to the biasing of transistors, a very questionable skill in today's surface mount semiconductor technology. While some might argue that these texts are good at developing problem solving skills, this author would maintain that the same could be said about a calculus text that has no contextual connection to the practical applications of this form of mathematics.

On a related note, one can point to the recent success of the Cisco Networking Academy Program and argue that a great deal of its success was due to the fact that this program deals with networks on a system level and therefore fulfils some of the short comings of present day technician programs. Cisco designed a program to serve its needs since the skill sets they needed were not being taught by the present educational system. Many electronics/computer technology programs that had been experiencing declining enrollments have received a boost by embracing the Cisco program. However, this is only a short term solution. Once these programs have saturated the workplace, they will most likely become less popular unless the field begins to change more rapidly than it is today and the program content follows suit. A more systemic

\footnotetext{
"Proceedings of the 2005 American Society of Engineering Education Annual Conference and Exposition Copyright (C) 2005, American Society of Engineering Education"
} 
approach to transform how electronics technology is taught and the topical areas that should be covered is necessary for long term positive change.

VII. Some curricula ideas and models

At the moment, most electronics programs at the two year college level still embrace the approach of teaching electronics fundamentals as if the physical layer of a typical electronic system is inflexible and can still be economically maintained down to the legacy device level. As argued by this author, the physical layer has already evolved beyond this basic level for many if not a majority of recently designed electronics systems. Therefore the approach to how we teach this material must change if the electronics technician of the future is to possess the requisite skill sets needed to deal with the systems of today and the future.

For basic electronics fundamentals courses (i.e. DC and AC circuit theory, analog and digital electronics, etc), it is this author's contention that the course content and the level and depth it needs be covered to should be the subject of a comprehensive technical education/industry summit. This summit would have as an immediate goal: the joint definition of just what the proper basics are and as a longer term goal a certification tool to test for that knowledge. This redefining does not mean that we discard old knowledge. It just means that one would have to "drill down" deeper to retrieve it in a modern information system if a deeper understanding is needed. The material in electronics devices courses should emphasis system models and input output system characteristics (e.g. the amplifier is treated as a gain block with certain inputoutput characteristics, etc). Again, if additional details are desired, one drills down deeper for the information. The higher level courses should also emphasis a system's level approach with classroom emphasis placed upon the interactions between the various sub-system units. Input from the industrial advisory boards as to the relative importance of currently offered topics is a must. Early on, inter-disciplinary topics need to receive coverage and be integrated into the curricula. Lastly, each graduate should have complete command of the PC. By this, I mean that the technician is able to use the PC to solve problems, acquire data, communicate through a network, and he/she is able up-grade a modern PC with both hardware and software as needed.

I believe that several acceptable models presently exist for the electronics programs of the future. One such model is provided by the Ford Asset Program (see www.fordasset.com ). This program was developed through a partnership of the Ford Motor Company and local community colleges to develop a base of service technicians that can work on manufacturer specific products. Ford and other car manufacturers learned long ago that it wasn't economical to rebuild your car starter. It is simply replaced if it fails. In this program, an automotive sub-system is dealt with as a functional unit that has a certain purpose that supports the overall operation of the vehicle. The details of its operation and physical construction aren't as important as they used to be! We should follow this lead when we discuss electronics systems. Another model program is the Verizon NextStep Program (see www.nspinfo.com ). This industry specific program was developed through a partnership between the Verizon Corporation and a consortium of New England and New York community colleges. Verizon employees attend school one day a week as part of their job responsibilities as they pursue an Associates Degree in Telecommunications Technology. The curriculum has been designed through interaction between the faculty that teach in the program and various company representatives. The electronics basics that are taught

\footnotetext{
"Proceedings of the 2005 American Society of Engineering Education Annual Conference and Exposition Copyright (C) 2005, American Society of Engineering Education"
} 
in this program reflect the world of work that the Verizon employees encounter. Besides using an innovative curriculum, this program places a heavy emphasis on employee soft skills. Integrated within the curriculum are numerous projects and assignments designed to increase the student's communication skills, leadership qualities, problem solving ability, and other soft skills.

VIII. Conclusion

What about today's electronics engineering technology teaching fraternity? Will they be quick to embrace change? I think the answer to that question is, most likely not. However, there are a large percentage of these faculty that are nearing retirement and they will begin to fade away through attrition. The younger replacement faculty that are hired will most likely be more open to change and have a better handle on the type of technician skills that are needed by today's industry. In the meantime, regional and national workshops and focus groups of both faculty and industry representatives need to be held. The purpose of these meetings will be to initiate a dialogue between the stakeholders of tomorrow's technical education system and to present the newest knowledge about teaching techniques and industry directions. It is important that a consensus exists between these groups because only then will positive change be possible and the educational template for the workforce of tomorrow be solidified. If possible, acquisitions editors for electronics texts should be invited to observe the outcomes of these workshops. Thereafter, the marketplace will provide the necessary filtering of the next generation of texts. What about today's laboratory experiments and exercises? Recently, several new texts have appeared that integrate fundamental concepts with devices and systems. This should be the path that is followed. Too many of today's basic electronics laboratory manuals are without any contextual basis whatsoever. Furthermore, higher level courses should embrace complex projects with emphasis on the integration of systems and cross disciplinary topics.

How will all this happen? Most likely funding from some large industrial foundation or the National Science Foundation will be necessary to start the process. This type of change in curriculum development and program content is already evolving in other technology areas with the help of existing NSF advanced technology education (ATE) centers like the National Center for Telecommunications Technologies (NCTT) and its regional partners ${ }^{[7]}$. For the electronics field, it won't be an easy task nor will it be a rapid transition. However, that being said, the longer this process is put off, the further apart the split becomes between what is being taught and what should be taught.

This paper is meant to provoke some thought and dialogue about this topic. The author doesn't claim to know the best solution to the perceived problem or for that matter the correct mix of circuit detail to system level material. However, there is a growing body of anecdotal and objective evidence that there is definite disconnect between the graduates of typical electronics technology programs and the world of work that they enter into.

References:

1. "Electronics Technology: A Suggested Two-Year Pos-High School Curriculum", Occupational Branch, Division

"Proceedings of the 2005 American Society of Engineering Education Annual Conference and Exposition Copyright (C) 2005, American Society of Engineering Education” 
of Vocational and Technical Education, Bureau of Educational Assistance Programs, U.S. Office of Education, January, 1965

\section{Page 23 of Ref. 1}

3. What Work Requires of Schools: A SCANS Report for America 2000, United States Department of Labor, June, 1991

4. Web site reference: www.nae.edu

5. Web site reference: www.gigascale.org

6. Same as Ref. 5

7. Web site reference: $\underline{\text { www.nctt.org }}$

Gary J. Mullett is a Professor of Electronics Technology at Springfield Technical Community College. For the past seven years he has been a Co-Director of the National Center for Telecommunications Technologies an NSF Advanced Technology Education Center of Excellence located at Springfield Technical Community College, Springfield, MA. He also serves as the New England curriculum coordinator for the Verizon NextStep Program. 